\title{
LA PRIMACÍA DE LA PRÁCTICA DE LA VIDA SOBRE LA CONTEMPLACIÓN DE LA VERDAD EN EL PROYECTO FILOSÓFICO CARTESIANO
}

\section{THE PREEMINENCE OF THE PRACTICE OF LIFE OVER THE CONTEMPLATION OF TRUTH IN THE CARTESIAN PHILOSOPHICAL PROJECT}

\author{
Sergio García Rodríguez ${ }^{1}$ \\ Universitat de les Illes Balears
}

Recibido: 30/08/2016

Aceptado: 11/01/2017

Resumen: Habitualmente se ha interpretado que el eje sobre el que se circunscribe la filosofía de Descartes es la búsqueda de la verdad en forma de certeza metafísica, permitiendo así la fundamentación segura del conocimiento. El presente artículo cuestiona esa lectura, sosteniendo que la propuesta epistemológica cartesiana representa un instrumento para perfeccionar la conducción ordinaria del sujeto ante los avatares de la vida ordinaria, concluyendo con una noción de certeza cuyo estatuto falible y sujeto a revisión guiará las acciones del sujeto en el mundo.

Palabras clave: certeza moral; contemplación de la verdad; falibilismo; intervención en el mundo; práctica de la vida.

\begin{abstract}
It has been usually interpreted that the axis on which the philosophy of Descartes is centered is the search for truth in the form of a metaphysical certainty, allowing the safe foundation of knowledge. This paper questions that reading, arguing that the Cartesian epistemological proposal represents an instrument to improve the conduction of the subject in the vicissitudes of ordinary life, concluding with a sense of certainty, whose fallible status will guide his actions in the world.
\end{abstract}

Keywords: conduction of life; contemplation of truth; fallibilism; intervention in the world; moral certainty

1. (sergio.garcia@uib.es) Doctorando en Filosofía (Universitat de les Illes Balears). Últimas publicaciones: (2016): «Dueños y poseedores de la naturaleza: la relación artificial-natural en la Dióptrica de Descartes», Contrastes. Revista internacional de filosofía, Vol. XXI, (En prensa). (2016): «Justificación y error en Descartes: un argumento pragmatista en la validación cartesiana del criterio de claridad y distinción», Revista de filosofía, Vol. 41, № 1, pp.97-109. (2015): «Los conceptos de "hecho" y "consecuencias útiles" en la crítica russelliana a la teoría de la verdad pragmatista de William James», Estudios filosóficos, LXIV, pp. 299-322. 


\section{Descartes y la preocupación por la práctica frente a la contemplación}

El Renacimiento constituye un periodo transitorio ${ }^{2}$ de conflicto intelectual entre las distintas mentalidades hegemónicas presentes en la Edad Media y la Modernidad, cuya mayor expresión se produce en relación a las cosmovisiones que cada una encarna y que serán determinantes respecto al papel que el sujeto posee en el mundo. Por un lado, la Edad Media representa, a grandes rasgos, una época donde la concepción imperante estima el conocimiento como un elemento valioso por sí mismo. Se trata, en definitiva, de una perspectiva que sitúa como fin de la vida humana la contemplación de la verdad, pues, según afirma Agustín de Hipona, «la vida bienaventurada no es otra cosa sino gozo de la verdad [...] Esta vida bienaventurada todos la querrían, esta vida que sola es bienaventurada todos la apetecen y todos buscan gozo de la verdad $\iota^{3}$. En efecto, el sujeto medieval se caracteriza por una consideración transitoria de la vida terrenal donde la actividad a la que éste se debe es a la contemplación de la verdad -ideal que se perpetuará a través de obras como La consolación de la filosofía de Boecio o el De Vita Contemplativa de Filón de Alejandría. Contrariamente, la Modernidad encarna el triunfo definitivo de la concepción renacentista del conocimiento, pues «la tendencia principal del pensamiento renacentista era abandonar el ideal monástico medieval de la contemplación y reemplazarlo por el ideal moderno de la acción, esto es, una praxis iluminada por el pensamiento y la experiencia» ${ }^{4}$. El conocimiento constituye para los novatores una poderosa herramienta de transformación del mundo, y no un mero objeto de veneración, según se observa en la máxima baconiana «el conocimiento es poder».

El proyecto cartesiano, en tanto que constitutivo de la Modernidad, representa la implantación definitiva de la cosmovisión activa del sujeto renacentista donde, frente a la mera contemplación de la verdad, los hombres anhelan la intervención en el mundo a fin de ponerlo a su servicio. En este sentido, la comparación que realiza Descartes entre su propuesta

2. Se utiliza la expresión "periodo transitorio" en tanto que, como afirma Kristeller, en el Renacimiento precisamente no prima de forma decisiva ninguna de las dos cosmovisiones dado que hallamos diversos autores que defienden distintas cosmovisiones como Pico della Mirandola o Giordano Bruno: "Speaking more broadly, I do not think that the respective claims of the contemplative and the active life have been settled once and for all by the Renaissance in favor of the active life. These are competing ideals which are rooted in human nature, and the contemplative life has had its advocates among the leading philosophers of all times» (Kristeller, P.O.: "Philosophy and Humanism in Renaissance Perspective» en O'Kelly (ed.): The Renaissance Image of Man and the World, Ohio: Ohio State University Press, 1966, p.44).

3. Agustín de Hipona: Confesiones, Madrid: Gredos, 2010, 10, 23, 33.

4. Kristeller, P.O.: op.cit., p.42

Thémata. Revista de Filosofía $\mathrm{N}^{\circ} 56$ (2017) pp.: 103-126. 
científica y la aristotélica pone de manifiesto el conflicto entre dos concepciones diferentes del conocimiento. La ciencia aristotélica, si bien representaba una alternativa ampliamente explicativa capaz de dar cuenta de multitud de fenómenos, conforma para Descartes una paradigma cuyo potencial práctico es escaso ${ }^{5}$, dado que "nadie ha tenido éxito en derivar algún beneficio práctico de la "materia primera", "formas substanciales", "cualidades ocultas" y similares»", concluyendo que, a través de los principios del aristotelismo, "no ha cabido realizar progreso alguno por medio de ellos después de haber sido respetados durante siglos» ${ }^{7}$. Así, frente a esta limitación práctica para ofrecer resultados, la Nueva Ciencia cartesiana estará comprometida con la intervención en el mundo, planteando como objetivo central el:

hacernos como dueños y poseedores de la naturaleza. Lo cual es muy de desear, no sólo por la invención de una infinidad de artificios que nos permitirían gozar sin ningún trabajo de los frutos de la tierra y de todas las comodidades que hay en ella, sino también principalmente por la conservación de la salud ${ }^{8}$.

Bajo la ciencia cartesiana subyace, de hecho, una nueva comprensión vital del hombre que posibilita otorgar sentido a la intervención del sujeto en el mundo. El hombre cartesiano ya no se contentará con una concepción de la vida como mero tránsito hacia lo ultraterrenal, sino que efectuará una revalorización de la vida terrenal (AT II, p.480; III, p.580) dado que «en esta vida nos suceden siempre más bienes que desdichas» ${ }^{9}-$,

5. De hecho, la crítica al aristotelismo apelando a la falta de resultados que produce su ciencia será una constante en la Modernidad: Schmitt, C.: "Philosophy and science in sixteenth-century universities: some preliminary comments» en Murdoch, J. (ed.): The Cultural Context of Medieval Learning, Boston: Reidel Publishing Company, 1975, p.489.

6. Las referencias de la obra de Descartes expuestas en las notas al pie se acogerán a la edición clásica de Adam \& Tannery - a partir de ahora AT- (Oeuvres de Descartes (XII Vol.), Adam, C. \& Tannery, P. (eds.): París: Leopold Cerf, 1897-1913). Así, se indicará que la referencia pertenece a AT, junto con el correspondiente volumen y página. Las traducciones expuestas en el texto se realizarán, salvo que se indique una traducción propia, en base a la edición de Cirilo Flórez (Descartes, Flórez, C. (ed.): Madrid: Gredos, 2011), indicando su página correspondiente. La Dióptrica y los Principios de la Filosofía se ceñirán a la traducción de Guillermo Quintás (Discurso del método, Dióptrica, Meteoros y Geometría, Quintás, G. (trad.): Madrid, Alfaguara, 1981; Principios de la filosofía, Quintás, G. (trad.), Madrid, Alianza Editorial, 1995). La traducción de las Séptimas Respuestas corresponde a la traducción de Vidal Peña: (Meditaciones metafísicas, Peña, V. (trad.): Madrid: Alfaguara, 1977). Descartes, "Carta a Voetius de mayo de 1643" (AT VIII-B, p.26) [Mi traducción]

7. Descartes: Principios de la filosofía, p.18 (AT IX-B, pp.18-9)

8. Descartes: Discurso del método, p.142 (AT VI, p.62)

9. Descartes: «Carta a la princesa Isabel del 3 de noviembre de 1645», p.616 (AT IV, p.333)

Thémata. Revista de Filosofía $\mathrm{N}^{\circ} 56$ (2017) pp.: 103-126. 
dirigiendo gran parte de los frutos resultantes de su ciencia a la preservación de la vida (AT I, p.645; I, p.649; V, p.178). Con todo, Descartes no deseará simplemente vivir, sino la consecución de una buena vida (AT IV, p.282; VI, p.22; IX-B, p.13) - pues «debemos sobre todo bien vivir» ${ }^{10}$. La buena vida representará el objetivo hacia el que se encamine la transformación cartesiana del mundo que desempeñe el sujeto, ejerciendo como criterio de demarcación respecto a la correcta intervención en el mundo. En definitiva, para Descartes, el conocimiento ya no es valioso en sí mismo, sino por sus aplicaciones prácticas que facilitan la obtención de consecuencias útiles, subordinando, consecuentemente, la teoría a la práctica hacia la conquista de los frutos del árbol de la filosofía (AT IX-B, pp.14-5).

Esta lectura se enfrenta con la interpretación más usual del proyecto filosófico cartesiano, articulada a través de lo que Williams ha denominado la figura del investigador puro - que, en una línea aristotélica, "pierde todo interés que no sea el interés por el conocimiento [en sí mismo]» ${ }^{11}$. Desde esta perspectiva, se propone como eje central del planteamiento filosófico cartesiano la búsqueda del conocimiento mediante la obtención de unos fundamentos epistémicos seguros sobre los que construir un nuevo edificio gnoseológico. El descubrimiento de las certezas últimas constituye el elemento estructural que otorga sentido al resto del proyecto cartesiano, dado que el investigador puro "se presenta cuidadosamente a sí mismo en una situación en la que se dedica sólo a investigar, no teniendo, en la medida que el ejercicio continúa, ningún otro interés añadido [...] su instrumento de investigación reflexiva, no será llevada hacia asuntos prácticos $»^{12}$.

El objetivo del presente artículo tratará, sin embargo, de subvertir la interpretación del investigador puro, defendiendo que en el proyecto cartesiano existe una primacía de la práctica de la vida sobre la contemplación de la verdad. Ello supondrá extender el influjo de la cosmovisión activa del sujeto más allá de la consecución de consecuencias útiles en la dimensión científica, redefiniendo en términos prácticos los objetivos de su propuesta filosófica, dado que «Descartes expresa un genuino interés en la conducta de la vida, presentándola como el objetivo principal de su empresa intelectual ${ }^{13}$. Esta tesis abordará el carácter fundamentalmente práctico de la filosofía de Descartes, cuyo objetivo central será facilitar nuestra correcta conducción ante los avatares de la vida ordinaria. Se trata, en

10. Descartes: Principios de la filosofía, p.15, (AT IX-B, p.13)

11. Williams, B.: Descartes. El proyecto de la investigación pura, Madrid: Cátedra, 1996, p.59

12. Ibid.: pp.58-9.

13. Naaman-Zauderer, N.: Descartes' Deontological Turn. Reason, Cambridge: Cambridge University Press, 2010, p.152.

Thémata. Revista de Filosofía $\mathrm{N}^{\circ} 56$ (2017) pp.: 103-126. 
definitiva, de reemplazar la visión de un Descartes centrado primordialmente en la obtención de un conocimiento definitivo, por una comprensión de su filosofía vinculada a la práctica de la vida. Para ello, la estrategia consistirá en un análisis del planteamiento metafísico cartesiano donde se evidencie cómo cada elemento epistemológico se halla inexorablemente vinculado a las acciones de la vida ordinaria.

\section{Los límites de la duda escéptica cartesiana: la práctica de la vida}

El escepticismo constituye el punto de partida de la filosofía cartesiana en tanto que permite acometer una serie de tareas precisas para la fundamentación segura del nuevo conocimiento. Diversos intérpretes, como Broughton o Wilson, han planteado dos lecturas posibles del papel de la duda pirrónica, cuyo estatus real o imaginario es planteado por Descartes de forma ambivalente. Por un lado, la interpretación ficticia sostiene que el escepticismo representa un método utilizado por Descartes a fin de suprimir los prejuicios de la infancia (AT VI, p.10; VIII, pp.35-7; IX, p.179) con vistas a obtener los principios últimos del conocimiento. Bajo esta lectura, la duda no representa un problema real, pues es hiperbólica, esto es, se trata de una exageración ridícula e irreal ${ }^{14}$ que Descartes plantea por sus intereses discursivos. De hecho, la caracterización efectuada por Descartes reitera en numerosas ocasiones la exageración que representa la propia duda radical (AT VI, p.32; VII, p.21; VII, p.144), afirmando incluso que "todas las dudas de estos días [son] hiperbólicas y ridículas»" ${ }^{15}$. Consecuentemente, la duda hiperbólica representaría "sobre todo, una técnica meditativa, una forma de terapia de pensamiento encaminada a tratar la excesiva confianza de la mente en los sentidos» ${ }^{16}$, de forma que, «se supone que es "real" en el sentido de poseer una especie de significado experiencial para el sujeto que piensa»" ${ }^{17}$.

Contra esta lectura, el presente artículo sostiene que el escepticismo representa para Descartes una preocupación real en tanto que posee un impacto efectivo en la vida del sujeto y no se reduce a un ámbito

14. Broughton compara la duda hiperbólica con un juego - resaltando así su carácter ficticio-, de forma que: «The player winds up suspending judgment about things it would be quite reasonable to believe. This would be ridiculous behavior if she weren't playing the game. But because she is playing the game, her suspense of judgment makes sense» (Broughton, J.: Descartes's Method of Doubt, Princeton: Princeton University Press, 2002, pp.49-50)

15. Descartes: Meditaciones metafísicas, p.220 (AT VII, p.89)

16. Kenny, A.: Descartes. A study of his philosophy, New York: Random House, 1968, p.34.

17. Wilson, M.: Descartes, London: Routledge \& Kagan Paul, 1978, p.228.

Thémata. Revista de Filosofía $\mathrm{N}^{\circ} 56$ (2017) pp.: 103-126. 
meramente teórico-metafísico. En efecto, si algo se evidencia en la crisis pirrónica del siglo XVII es la huella que el escepticismo deja en las esferas filosófica y religiosa, cuya traslación implica, de hecho, efectos transformadores de la realidad del momento. Por ejemplo, el pirronismo conforma el instrumento utilizado por la Reforma a fin de instaurar la crisis del criterio - que suprimía la existencia una única lectura de la Biblia correcta-, planteando el problema de "cómo sabemos cuál es la regla de fe, la norma por la cual pueda distinguirse la verdadera fe de la falsa fe. Lutero y Calvino habían desafiado el criterio de la Iglesia» ${ }^{18}$. La introducción del escepticismo en la dimensión religiosa conlleva, así, el reemplazo de la interpretación correcta y única de la Iglesia por la libre exégesis de los textos sagrados propia del protestantismo. Otro caso del impacto real del escepticismo se halla en la traslación de sus efectos a la vida ordinaria de los sujetos, afectando a la toma de decisiones vitales. Ante la falta de conocimientos verdaderos, un escéptico podía tomar la salida de la suspensión del juicio (epoché), evitando pronunciarse respecto a cualquier cuestión. Así, una epoché llevada hasta sus últimas consecuencias podía conllevar serias deficiencias para la práctica vital de un individuo. Descartes ilustra una suspensión del juicio radical a través del ejemplo de Pirrón ${ }^{19}$, cuyos efectos comprenden la vida ordinaria del sujeto, representando a aquellos «escépticos que se desinteresaban hasta tal punto de las cosas del mundo, que, para impedir que se arrojasen ellos mismos a los precipicios, debían ser cuidados por sus amigos ${ }^{20}$. Por tanto, el planteamiento contextual de la crisis pirrónica pone de manifiesto la capacidad de la duda escéptica para transformar la realidad, cuyos efectos prácticos se oponen a una concepción de la misma en términos meramente ficticios.

El proyecto filosófico cartesiano requiere enfrentarse ante el reto que supone el escepticismo pirrónico a fin de establecer los fundamentos seguros sobre los que construir el conocimiento. Para ello, Descartes se ve obligado a plantear su duda metódica en los términos más radicales a fin superar el escepticismo pirrónico. El zénit escéptico cartesiano es introducido mediante el argumento del genio maligno, pues permite cuestionar la propia naturaleza del sujeto a la hora de obtener percepciones claras y dis-

18. Popkin, R.: La Historia del Escepticismo desde Erasmo hasta Spinoza, México: Fondo de Cultura Económica, 1983, p.119.

19. La referencia de Descartes concuerda con la descripción de Pirrón realizada por Diógenes Laercio: «Era consecuente con esto en su vida, sin desviarse ni tomar precauciones ante nada, enfrentándose a cualquier cosa, a lo que le saliera al paso, tanto carros como precipicios y perros, con total inadvertencia de sus sensaciones. Sin embargo le ponían a salvo, según dicen los seguidores de Antígono de Caristo, sus amigos que le acompañaban» (Diógenes Laercio: Vidas de los Filósofos Ilustres, Madrid: Alianza, 2011, IX 62).

20. Descartes: Meditaciones metafísicas, p.386 (AT VII, p.351)

Thémata. Revista de Filosofía ํ56 (2017) pp.: 103-126. 
tintas en tanto que «tal vez algún dios había podido darme tal naturaleza que siempre me engañase con respecto a las cosas que me parecen más evidentes ${ }^{21}$. De este modo, dicho argumento extiende una duda incluso ante aquellos fenómenos que percibimos con certeza muy segura - como las matemáticas (AT VII, pp.20-1; IX-B, pp.26-7)-, estableciendo una incertidumbre más radical que aquella referida a nuestras sensaciones a través del argumento del sueño. Ante la envergadura de la duda cartesiana, parece factible suponer que su extensión debiera comprender la práctica ordinaria de los sujetos - suspendiendo el juicio en las dimensiones vital e intelectual para prevenir el error. A fin de evitar dicha situación, Descartes introduce una distinción entre "práctica de la vida» y "conocimiento de la verdad» (AT II, p.35; III, p.335; VI, p.31; VII, p.149; VII, pp.350-1; VIII, p.5; IX-B, p.7), instaurando unos límites definitivos a su argumento escéptico, donde se dilucida la extensión posible de la epoché. Dicha diferenciación se traduce en una escisión entre el ámbito de la metafísica y el de la vida ordinaria, donde se excluye a ésta última de los confines de la duda radical, pues «En modo alguno debemos hacer extensiva esta duda al gobierno de nuestras acciones» ${ }^{22}$. Dado el carácter real de la duda escéptica y el que "las acciones de la vida no admiten demora» ${ }^{23}$, Descartes sostiene que las decisiones que el sujeto ordinariamente adopta no pueden estar sujetas a una suspensión, pues ello implicaría arriesgar su vida por un mero pretexto metafísico. La prudencia constituye la máxima que debe guiar el proceder ordinario del sujeto ${ }^{24}$ (AT IV, pp.356-7), de forma que la extensión de la epoché a la práctica de la vida supondría precisamente atentar contra ese principio (AT IX-B, p.6), conduciendo a situaciones peligrosas para la conservación de la buena vida:

debería ser tachado sin duda de loco y suicida quien quisiera abstenerse de todo alimento hasta consumirse de hambre, por no tener la certeza de que no se les hubiese mezclado algún veneno, y pensara que no es culpable de su consunción porque no sería claro y evidente de que tendría ante sí el sustento de su vida, y de que es mejor esperar la muerte ayunando que matarse comiendo ${ }^{25}$.

21. Descartes: Meditaciones metafísicas, p.179 (AT, IX-A, p.28)

22. Descartes: Principios de la filosofía, p.22 (AT IX-B, p.26)

23. Descartes: Discurso del método, p.118 (AT VI, p.25)

24. Brown vincula la prudencia cartesiana a la phronesis aristotélica (sabiduría práctica): Cf. Brown, D.: Descartes and the Passionate Mind, Cambridge: Cambridge University Press, 2006, pp.193-5. A este mismo respecto, Marion destaca la importancia que este principio práctico desempeña respecto a la constitución del conocimiento científico: Cf. Marion, J.L.: Sur l'Ontologie Grise de Descartes, París: Vrin, 2000, pp.33-4.

25. Descartes: «Carta a Hyperaspistes de agosto de 1641», pp.393-4 [trad. Olaso] (AT III, p.422)

Thémata. Revista de Filosofía $\mathrm{N}^{\circ} 56$ (2017) pp.: 103-126. 
En este punto cabe plantearse cuáles son las razones que inducen a Descartes a plantear una distinción donde se excluye de la duda radical el ámbito de la vida ordinaria. La tesis que se sostendrá defiende que la supresión de las acciones de la vida del ámbito de la duda radical se fundamenta en la preeminencia cartesiana de la práctica de la vida sobre el conocimiento. La cosmovisión del sujeto activo a la que Descartes pertenece conlleva una redefinición de sus objetivos vitales, reemplazando la mera contemplación de la verdad por la práctica y la intervención en el mundo para someterlo a sus designios. Si el fin del proyecto cartesiano es, en definitiva, la consecución de una buena vida, ésta es, sin embargo, incompatible con la instauración de una epoché que comprenda los asuntos relativos al orden práctico de la vida, pues vivir bien requiere que el sujeto tome decisiones ante encrucijadas vitales "porque la vida no tolera dilaciones y, además, porque debemos intentar sobre todo bien vivir ${ }^{26}$. El caso de la moral provisional expuesta en el Discurso es el que mejor ilustra la exclusión de la dimensión vital, dado que, ante la duda radical donde se rechaza "como absolutamente falso todo aquello en que pudiera imaginar la menor duda» ${ }^{27}$, enuncia una serie de reglas prudenciales que el sujeto debe seguir independientemente de su verdad y que le permiten gozar temporalmente de una buena vida por los resultados prácticos que se extraen de las mismas:

Por último, como para empezar a reconstruir el alojamiento en donde uno habita, no basta haberlo derribado y haber hecho acopio de materiales y de arquitectos [...] sino que también hay que proveerse de alguna otra habitación en donde pasar cómodamente el tiempo que dure el trabajo; así, pues, con el fin de no permanecer irresoluto en mis acciones, mientras la razón me obligaba a serlo en mis juicios, y no dejar de vivir, desde luego, con la mejor ventura que pudiese, hube de arreglarme una moral provisional ${ }^{28}$.

Por tanto, las decisiones de la vida ordinaria no pueden quedar suspendidas hasta lograr el conocimiento de las certezas indubitables, dado que «sucede las más de las veces, cuando el negocio emprendido es interesante, que su oportunidad acaba por perderse mientras demoramos la ejecución ${ }^{29}$. De esta forma, el sujeto cartesiano está obligado a actuar (AT II,

26. Descartes: Principios de la filosofía, p.15 (AT IX-B, p.13).

27. Descartes: Discurso del método, p.123 (AT VI, p.31)

28. Ibid:: p.117 (AT VI, p.22)

29. Descartes: «Carta a la princesa Isabel de mayo de 1646», p.629 (AT IV, p.415)

Thémata. Revista de Filosofía №56 (2017) pp.: 103-126. 
p.35; VI, p.25; IX-B, p.13) a fin de lograr los mejores frutos de sus prudentes acciones, "pues las ocasiones oportunas para actuar casi siempre pasarían antes de que pudiéramos vernos libres de todas nuestras dudas» ${ }^{30}$. En este sentido, la moral provisional constituye un instrumento que busca facilitar la praxis del sujeto en el mundo, proponiendo unas reglas eminentemente prácticas donde la verdad no es el elemento primordial sino el conducirse de la mejor forma - como se ejemplifica en la primera máxima: «seguir las leyes y las costumbres de mi país, conservando con firme constancia la religión» ${ }^{31}$, pues «lo más útil era acomodarme a aquellos con quienes tendría que vivir» ${ }^{32}$. La inclusión de la práctica de la vida bajo la duda radical representa, consecuentemente para Descartes, una mera extravagancia propia de personas que han perdido el juicio (AT III, p.422; VII, p.460; VII, p.548; IX-B, p.6), «los cuales van más allá de todos los límites de la duda» ${ }^{33}$, en tanto "que menosprecia[n] conducirse con prudencia» ${ }^{34}$. Bajo esta lectura, la duda no puede suprimir el ámbito vital del hombre pues, como más adelante se defenderá, el propósito último de ésta se halla intrínsecamente ligado al perfeccionamiento de nuestra práctica ordinaria.

Por último, siguiendo el análisis de Kenny, cabría cuestionarse si, tras extraer el ámbito de la práctica de la vida de la duda radical, es posible afirmar que se trata de una duda real, «porque dado que la duda no encuentra expresión alguna en la acción, ella es algo menos que una genuina suspensión del juicio» ${ }^{35}$. Contrariamente, es debido a que se establece esa distinción por lo que se trata una duda real. Descartes es consciente del peligro que entraña el reto escéptico y se ve obligado a abstraer la dimensión vital del ser humano a fin de evitar los efectos reales y perniciosos que pudieran acarrear a nuestra conducta ordinaria. Si la duda representara un mero ejercicio ficticio -sin implicaciones prácticas-, propuesto para hallar los fundamentos del conocimiento, no tendría sentido que se planteara dicha distinción, dado que la duda no entrañaría riesgo alguno para las acciones de la vida. Con todo, es cierto que Descartes parece sostener en diversas ocasiones la irrealidad de la misma, lo que ha llevado a intérpretes como Wilson a sostener una incoherencia en el propio planteamiento cartesiano ${ }^{36}$. Sin embargo, se debe reafirmar el carácter real del reto escéptico cartesiano, defendiendo que las afirmaciones sobre la irrealidad

30. Descartes: Principios de la filosofía, p.22 (AT IX-B, p.26)

31. Descartes: Discurso del método, p.117 (AT VI, pp.22-3)

32. Ibid.: p.117 (AT VI, p.23)

33. Descartes: Meditaciones metafísicas, p.417 [trad. Peña] (AT VII, p.548)

34. Descartes: Principios de la filosofía, p.10 (AT IX-B, p.6)

35. Kenny, A.: op. cit., p.23

36. Cf. Wilson, M.: op. cit., p.46.

Thémata. Revista de Filosofía $\mathrm{N}^{\circ} 56$ (2017) pp.: 103-126. 
de la duda representan una estrategia retórica. La fragilidad en la que la crisis pirrónica había sumido a la filosofía escolástica, rompiendo el compromiso religioso ${ }^{37}$ asumido por la filosofía institucionalizada a fin de ofrecer el sustento teórico del cristianismo, implicó que la acusación más reiterada contra los escépticos del siglo XVI-XVIII fuera la de ateísmo como sucedió en el caso de Charron-, dado que «cualquier ataque a esta filosofía sería entendido como un agravio a los fundamentos de la teología ${ }^{38}$. Asimismo, conviene recordar que Descartes se sirve en sus Meditaciones de hipótesis arriesgadas como la del Dios engañador (AT VII, p.21), o incluso de la necesidad de probar la existencia de Dios -lo que implicará para algunos de sus críticos el negar temporalmente la misma (AT IV, p.536). Este representa uno de los momentos más espinosos de su propuesta filosófica, de modo que, para evitar la acusación de impiedad, se sostendrá que Descartes se vio obligado a recalcar constantemente el carácter ficticio de las dudas, donde «todo lo que se ha dicho aquí de Dios es una fábula»" ${ }^{39}$-lo que no impidió que "ciertos teólogos, tanto en Utrecht como en Leyden, denunciaran el escepticismo del filósofo francés como un disfraz del ateísmo ${ }^{40}$ pues Voetius y Bourdin le acusarán de ateo (AT IV, p.536). La atribución a la duda de un carácter irreal y exagerado constituye así un recurso retórico utilizado por Descartes a fin de que no se cuestione su fe -recordemos que las Meditaciones incluso buscaron la aprobación de la Facultad de Teología de la Sorbona (AT III, pp.184-5; III, p.233; III, p.239; VII, pp.1-6). Por tanto, la duda posee un estatuto real para Descartes y todas las referencias que realiza de su carácter ficticio constituyen estrategias discursivas para evitar la acusación de ateísmo.

37. La filosofía institucionalizada del siglo XVII — fundamentalmente un aristotelismo de corte tomista - había asumido la tarea de defender filosóficamente la teología cristiana de los envites de la crisis escéptica y las nuevas filosofías, pues consideraban que ello podía suponer un riesgo para la hegemonía del Cristianismo. A este respecto: $C f$. Jolley, N.: «The relation between theology and philosophy", en Garber, D. \& Ayers, M. (eds.): The Cambridge History of Seventeenth Century Philosophy (Vol. I), Cambridge: Cambridge University Press, 1998, p.364.

38. Menn, S.: «The Intellectual Setting», en Garber, D. \& Ayers, M. (eds.): The Cambridge History of Seventeenth Century Philosophy (Vol. I), Cambridge: Cambridge University Press, 1998, p.35.

39. Descartes: Meditaciones metafísicas, p.168 (AT VII, p.21)

40. Dibon, P.: «Scepticisme et orthodoxie reformée dans la Hollande du Siècle d'Or» en Popkin, R., \& Schmitt, C. (eds.): Scepticism from the Renaissance to the Enlightenment, 1987, p. 57

Thémata. Revista de Filosofía $\mathrm{N}^{\circ} 56$ (2017) pp.: 103-126. 


\section{La distinción entre certeza moral y metafísica como fun- damento epistemológico de la práctica de la vida}

El proyecto epistemológico cartesiano del investigador puro inaugura la Modernidad al otorgar al problema de la fundamentación epistémica un cariz central que perdurará en la filosofía venidera. Bajo esta interpretación, el objetivo central de la filosofía de Descartes es el descubrimiento de la verdad absoluta, pues «no hay nada que sea valioso excepto el valor de la búsqueda de la verdad» ${ }^{41}$. Descartes «veía su misión en la vida como la del encargado de barrer los escombros de la opinión preconcebida a fin de construir un nuevo sistema de conocimiento basado en principios "claros y distintos" " ${ }^{42}$. Ante este desafío, la duda cartesiana adquiere una relevancia clara, erigiéndose en el método mediante el que «deshacerme de todas las opiniones a las que hasta entonces había dado crédito, y comenzar todo de nuevo desde sus fundamentos, si quería establecer algo firme y constante en las ciencias» ${ }^{43}$. La certeza metafísica representará el producto resultante de la duda hiperbólica que permitirá superar el argumento del genio maligno, conformando el fundamento epistemológico firme y seguro sobre el que sea posible asentar el resto del conocimiento humano.

Con todo, la lectura del proyecto epistemológico cartesiano centrada sobre la mera obtención de la certeza metafísica se ve cuestionada por la distinción entre "práctica de la vida» y «conocimiento de la verdad», dado que al erigirse una limitación práctica donde el ámbito de la vida ordinaria queda excluido de la epoché, se establece la necesidad de un conocimiento provisional que permita al sujeto la toma de decisiones y la consecución de las mismas en el mundo al margen de la certeza metafísica. El mundo obliga al sujeto a asumir decisiones de orden práctico de las que depende su supervivencia, por lo que éste no puede conformarse con la suspensión del juicio hasta la obtención de un conocimiento seguro pues "las constricciones de la vida cotidiana requieren a menudo que tomemos decisiones en función de propósitos prácticos, y no exclusivamente en vista del logro del conocimiento verdadero ${ }^{44}$. En consecuencia, se precisa una certeza en la dimensión ordinaria del sujeto capaz de dirimir los asuntos del orden práctico de la vida. Este conocimiento constituirá la denominada certeza moral, «suficiente para la práctica de la vida, y muy diferente, según he dicho a

41. Williams, B.: op. cit., p.59

42. Cottingham, J.: How to read Descartes, Croydon: Granta, 2008, pp.19-20

43. Descartes: Meditaciones metafísicas, p.165 (AT VII, p.17)

44. De Araujo, M.: Scepticism, Freedom and Autonomy, New York: Walter de Gruyter, 2003, p. 148

Thémata. Revista de Filosofía Nº56 (2017) pp.: 103-126. 
menudo, del saber metafísico ${ }^{45}$. En otras palabras, Descartes introduce la distinción entre «certeza metafísica» y "certeza moral» (AT IV, p.173; VI, pp.37-8; VII, p.475; IX-B, pp. 323-5) como el sustento epistémico que permite salvaguardar la escisión entre conocimiento de la verdad y práctica de la vida, garantizando la coexistencia de ambas esferas bajo objetivos epistémicos diferenciados. Esta distinción constituye el revulsivo de una comprensión de la epistemología cartesiana cuyo eje sea conformado exclusivamente por la certeza metafísica, pues implica el reconocimiento de una dimensión cuya vinculación con la verdad metafísica no se produce sensu stricto. Ciertamente, la certeza moral representa un conocimiento falible ligado a la práctica de la vida y, en este sentido, alejado de aquello que representa la certeza metafísica, lo que implica desmarcarse de la lectura de Markie que «define las certezas moral y metafísica en relación a un interés por la verdad ${ }^{46}$.

La relación entre la certeza moral y la práctica de la vida es establecida en reiteradas ocasiones por Descartes (AT VI, pp.24-5; VII, p.149; IX-B, p.26), constituyendo aquel conocimiento «suficiente para regular nuestras costumbres, o tan grande como [el] que tenemos acerca de las cosas que no tenemos costumbre de dudar en relación con la conducta de la vida ${ }^{47}$. Por un lado, la certeza moral la conforman aquellos conocimientos de los que se excluye la duda pues, aunque existan razones por las que pudieran ser incluidas bajo la epoché, ello implicaría serios problemas para la práctica ordinaria. El ejemplo más claro a este respecto es encarnado por los sentidos, de los que no podemos prescindir ordinariamente "porque cuando se trata de la conducción de la vida, sería una cosa por completo ridícula no referirse a los sentidos» ${ }^{48}$, pues "Toda la conducta de nuestra vida depende de nuestros sentidos» ${ }^{49}$. Así, aunque metafísicamente existan motivos para dudar de aquellas percepciones de las que nos proveen nuestros sentidos (AT I, p.350; II, p.599; VII, p.18; IX-B, p.7), debemos confiar en la certeza moral que nos proporcionan ordinariamente, pues habitualmente «se tiene mayor razón para creerlas que para negarlas» ${ }^{50}$-lo contrario entrañaría una práctica arriesgada e imprudente propia de locos (AT III, p.422; VI, pp.37-8). Por otro lado, la certeza moral conforma un código que permite al sujeto regular sus costumbres, según se ejemplifica en la moral provisional planteada en el Discurso (AT VI, pp.22-8). En ella, se

45. Descartes: Meditaciones metafísicas, p.360 [trad. Peña] (AT VII, p.475)

46. Markie, P.: Descartes's Gambit, Ithaca: Cornell University Press, 1986, p.52

47. Descartes: Principios de la filosofía, p.411 (AT IX-B, p.323)

48. Descartes: Meditaciones metafísicas, p.386 (AT VII, p.351)

49. Descartes: Dióptrica, p.59 (AT VI, p.81)

50. Descartes: Meditaciones metafísicas, p.169 (AT VII, p.22)

Thémata. Revista de Filosofía Nº56 (2017) pp.: 103-126. 
enuncian unas máximas cuyo «objetivo principal [...] es permitirnos conducir nuestras vidas lo más lejos posible, incluso mientras caminamos en la oscuridad ${ }^{51}$. Debemos recordar que el fin de las acciones del sujeto es la consecución de una buena vida; la certeza moral constituye así el mejor instrumento disponible para alcanzarla en vista de que, en el caso de la moral par provision, garantiza «no dejar de vivir, desde luego, con la mejor ventura que pudiese ${ }^{52}$. Ciertamente, la certeza moral representa un conocimiento probable (AT VI, p.25; VII, p.22; VII, p.73) -susceptible de ser falso-caracterizado por su falibilidad, en tanto que:

la necesidad de los asuntos nos obliga con frecuencia a determinarnos antes de que hayamos tenido tiempo para examinarlos tan cuidadosamente, hay que confesar que la vida del hombre se halla sujeta a fallar con mucha frecuencia en las cosas particulares, y, en fin, hay que reconocer la imperfección y debilidad de nuestra naturaleza ${ }^{53}$.

La urgencia de los asuntos ordinarios impele al sujeto a determinarse provisionalmente (AT VI, p.22; VI, pp.27-8; IX-B, p.7). Sin embargo, ello no es óbice para que, ante la aparición de juicios más correctos, no se efectúen sustituciones que perfeccionen la certeza moral, dado que nuestras opiniones «tampoco deben ser estimadas tan ciertas que no pue$\mathrm{da}[\mathrm{n}]$ modificarse [...] cuando a ello obliga la evidencia de alguna razón» ${ }^{54}$, permitiendo así «aumentar gradualmente mi conocimiento y elevarlo poco a poco hasta el punto más alto a que la mediocridad de mi ingenio y la brevedad de mi vida puedan permitirle llegar» ${ }^{55}$. En definitiva, la caracterización que es posible reconstruir de las referencias cartesianas concernientes a la certeza moral da cuenta de un conocimiento probable del que tentativamente el sujeto debe servirse hasta hallar uno mejor, por lo que es falible y susceptible de ser perfeccionado (AT VI, p.3; VI, p.24; VII, p.47) a fin de garantizar al sujeto la mejor toma de decisiones.

Ahora bien, asumiendo la distinción "entre las afirmaciones de conocimiento realizadas en el contexto de las circunstancias cotidianas, y las afirmaciones de conocimiento efectuadas en el contexto de una investigación filosófica $\rangle^{56}$, es preciso reafirmar la tesis cartesiana de la una primacía de la práctica sobre la contemplación de la verdad. Si bien la existencia

51. Naaman-Zauderer, N.: op. cit., p.164

52. Descartes: Discurso del método, p.117 (AT VI, p.22)

53. Descartes: Meditaciones metafísicas, p.220 (AT VII, p.90)

54. Descartes: Principios de la filosofía, p.11 (AT IX-B, p.7)

55. Descartes: Discurso del método, p.102 (AT VI, p.3)

56. De Araujo, M.: op. cit., p.157

Thémata. Revista de Filosofía N56 (2017) pp.: 103-126. 
de una certeza moral que se ve excluida - debido a la importancia de la dimensión vital del hombre - de la investigación de los fundamentos metafísicos evidencia que la práctica vital prima ante la discusión metafísica, sin embargo, la función de la certeza metafísica aún debe ser redefinida en relación a sus conexiones con la conducción de la vida. Aunque la certeza metafísica ha tendido a ser interpretada como el gran descubrimiento epistemológico de Descartes, no se debe perder de vista el objetivo práctico hacia el que ésta se encamina: el perfeccionamiento de la certeza moral. En efecto, Descartes afirma reiteradamente (AT IV, p.291; VI, p.10; VI, p.61; IX-B, p.2; X, p.361; X, p.496) el poder que la certeza metafísica posee para mejorar la forma de conducirnos por el mundo:

[...] por lo que toca a las opiniones, a las que hasta entonces había dado mi crédito, no podía yo hacer nada mejor que emprender de una vez la labor de suprimirlas, para sustituirlas luego por otras mejores o por las mismas, cuando las hubiere ajustado al nivel de la razón. Y tuve firmemente por cierto que, por este medio, conseguiría dirigir mi vida mucho mejor que si me contentase con edificar sobre cimientos viejos y me apoyase solamente en los principios que había aprendido siendo joven, sin haber examinado nunca si eran o no verdaderos ${ }^{57}$.

Consecuentemente, la certeza metafísica no representa sino un instrumento que contribuye a la práctica de la vida, cuyo fin es otorgar las herramientas al sujeto con que "distinguir lo verdadero de lo falso, para ver claro en mis actos y andar seguro por esta vida» ${ }^{58}$, pues «esperaba perfeccionar más y más mis juicios» ${ }^{59}$. Ahora bien, esta certeza no puede sustituir a la certeza moral, tan solo perfeccionarla, dado que «En lo que se refiere a la conducta de la vida debiera desearse tanta certeza como la que se necesita para adquirir la ciencia; pero, sin embargo, se demuestra muy fácilmente que en aquélla no se debe buscar ni esperar certeza semejante» ${ }^{60}$. De ese modo, las pretensiones que habitualmente se achacan a la certeza metafísica de constituir el fundamento del que derivar un conocimiento infalible se ven diluidas, pues, aunque la certeza metafísica conforma el fundamento último indubitable, la relación que posee con el resto del conocimiento - constituido por certezas morales- es únicamente de perfeccionamiento. Las certezas morales derivadas de las certezas me-

57. Descartes: Discurso del método, p.111 (AT VI, pp.13-4)

58. Descartes: Discurso del método, p.106 (AT VI, p.10)

59. Ibid.: p.118 (AT VI, p.24)

60. Descartes: «Carta a Hyperaspistes de agosto de 1641», p.393 [trad. Olaso] (AT III, p.422)

Thémata. Revista de Filosofía $\mathrm{N}^{\circ} 56$ (2017) pp.: 103-126. 
tafísicas permiten al sujeto realizar juicios más probables ${ }^{61}$, no obstante, el carácter falible del conocimiento humano indica que estamos siempre sujetos a errar. Ciertamente, Descartes reitera la falibilidad del conocimiento humano (AT VI, p.3; VI, p.68; VII, p.88; VII, p.90), lo que se traduce en unas certezas morales cuyo perfeccionamiento nunca podrá eludir absolutamente el error. El fin último del proyecto cartesiano refiere a la consecución de una buena vida, de forma que perfeccionar las certezas morales — elemento que guía las acciones del sujeto- constituye la mejor forma de lograr dicho fin. La certeza metafísica debe replantearse así respecto al papel que juega en relación a dicho objetivo, cuyo estatuto epistemológico es garantía de una mejora en nuestra forma de movernos por el mundo - sin suprimir la idea de que el conocimiento adquirido siempre estará en disposición de ser falso. En consecuencia, la certeza metafísica, en tanto que fundamento epistemológicamente seguro, no representa sino un conocimiento último que permite la mejora de la práctica ordinaria, pero que en ningún caso conlleva la supresión del error en ella: la certeza moral perfeccionada por la certeza metafísica continuará siendo certeza moral, esto es, falible.

En suma, la primacía de la práctica de la vida implica redefinir el papel de la certeza metafísica, pues el conocimiento de la verdad se encamina al perfeccionamiento de nuestras herramientas para tomar decisiones en la vida ordinaria - evitando aquellas interpretaciones ${ }^{62}$ donde se pretende una coexistencia separada de las esferas teórica y vital. La distinción entre tipos de certeza como estrategia para salvaguardar la dimensión metafísica y la dimensión ordinaria no impide que la certeza metafísica halle su sentido en relación a la práctica de la vida.

\section{La crítica cartesiana a la irresolución: la urgencia de los asuntos prácticos vitales}

Una vez abordada la cuestión de las certezas, origen del conocimiento que permite la toma de decisiones, el siguiente punto a considerar alude a la materialización de dicho conocimiento en la formulación de

61. Se responde así al problema de Ragland de que «if all our perceptions about how to direct our attention are somewhat unclear, then they cannot compel us to attend in any particular wayn (Ragland, C.P.: The Will to Reason. Theodicy and Freedom in Descartes, Oxford: Oxford University Press, 2016, p.152), pues el que sean más probables nos otorga un criterio de elección.

62. Autores como Guenancia perciben la distinción entre «práctica de la vida» y «contemplación de la verdad» como espacios alejados que se rigen por distintas reglas y que no manifiestan relación mutua alguna: Cf. Guenancia, P.: Lire Descartes, Paris: Gallimard, 2000, pp. $488-90$

Thémata. Revista de Filosofía Nº56 (2017) pp.: 103-126. 
juicios de los que dependerá la acción. Los juicios representan uno de los pilares de la propuesta epistemológica cartesiana, resultado de "una facultad de juzgar que nunca le permitiría equivocarse mientras el sujeto la utilizara correctamente» ${ }^{63}$, sobre la que se asentará la obtención de un conocimiento seguro. El correcto empleo de la facultad de juzgar logrará que el sujeto obtenga conocimiento, mientras que su uso inadecuado conducirá al error en los juicios formulados. Habitualmente, la interpretación ${ }^{64}$ que ha primado respecto a la comprensión cartesiana de los usos incorrectos de la facultad de juzgar se ha circunscrito al problema de la precipitación, donde la voluntad instiga un juicio en el que se produce una falta de adecuación entre entendimiento y voluntad que ocasiona el error en el mismo. Esta lectura aunque correcta es insuficiente, dado que Descartes afirma en diversas ocasiones (AT VI, p.18; VI, p.22) la existencia de una segunda variable a evitar al elaborar juicios: la irresolución. En efecto, según la primera regla del método, para Descartes es necesario en los juicios «evitar cuidadosamente la precipitación y la prevención ${ }^{65}$, pues, como se observará, cada uno de dichos errores traslada una serie de deficiencias a éstos. Previo al análisis de la precipitación y la irresolución debe destacarse que los juicios no deben concebirse exclusivamente en relación a la mera consecución de la verdad, en tanto que conforman a su vez el criterio de acción que guía el proceder del sujeto en el mundo, hallándose en relación tanto con el conocimiento de la verdad como con la práctica de la vida.

Precisamente atendiendo a dicha distinción es posible dilucidar en qué sentido cada uno de estos dos errores repercute en los juicios. La precipitación (AT VI, p.18; VI, p.22; IX-B, p.25; X, p.526) representa un mal uso de la facultad de juzgar donde la voluntad — cuya facultad de desear es infinita en comparación con el alcance limitado del entendimiento (AT VII, p.58; IX-B, p.40) - se determina "sobre algo que nuestro entendimiento no conoce en modo alguno» ${ }^{66}$, dando lugar a juicios donde se va "más allá de lo que nosotros conocemos clara y distintamente. Y cuando en forma de tal abusamos de la voluntad, no es maravilla alguna si nos equivoquemos» ${ }^{67}$. De otro modo, la precipitación constituye aquella inadecuación entre entendimiento y voluntad que induce al sujeto al error en sus juicios, lo cual conforma un problema respecto al conocimiento de la verdad, pues este uso deficiente de nuestras facultades constituye la causa principal de nuestros errores (AT VII, p.58; IX-B, p.39). Contrariamente, la irresolución no aten-

63. Naaman-Zauderer, N.: op. cit., p.62

64. Cf. Hamelin, O.: Le Système de Descartes, París: Félix Alcan, 1921, p.165

65. Descartes: Discurso del método, p.114 (AT VI, p.18)

66. Descartes: Principios de la filosofía, p.41 (AT IX-B, p.39)

67. Ibid.: p.42 (AT IX-B, p.40)

Thémata. Revista de Filosofía $\mathrm{N}^{\circ} 56$ (2017) pp.: 103-126. 
ta contra el conocimiento de la verdad, dado que «nos dispone a deliberar y tomar consejo» ${ }^{68}$ a fin de realizar juicios acertados. El problema de la irresolución refiere exclusivamente a la dimensión práctica de la vida, dado que, ante la urgencia de los asuntos ordinarios que requieren la toma de decisiones con inmediatez, ésta induce al sujeto a «emplea $[r]$ en deliberar el tiempo que se necesita para actuar» ${ }^{69}$. En consecuencia, la irresolución no es problemática debido a que, como ha sostenido Quintás, impida «fundar el juicio en ideas claras y distintas, primando el peso que se otorga a la memoria a los hábitos» ${ }^{70}$, sino en tanto que dificulta al sujeto determinarse por un juicio, evitando la realización de una acción debido a su indecisión, donde «su oportunidad acaba por perderse mientras demoramos la ejecución» ${ }^{71}$. Dado que los juicios conforman el instrumento tanto para obtener verdades como para determinar las decisiones prácticas, se pone de manifiesto que la precipitación y la prevención representan las dos formas posibles en que lastrar la doble tarea propia de los juicios: la precipitación induce al sujeto a errar, mientras que la excesiva prevención suprime la posibilidad de actuar cuando al sujeto lo impelen las circunstancias.

En este punto, se nos plantea el dilema de que el mundo nos sitúe ante la necesidad de realizar un juicio a fin de actuar a pesar de que no podamos afirmar con seguridad que sea realmente verdadero - como el ejemplo del alimento envenenado (AT III, p.422). Lo que esta situación representa, de hecho, es la elección entre la práctica de la vida o el conocimiento de la verdad como cometido principal que debe prevalecer en los juicios. Si bien Descartes sugiere la epoché, consistente en "sostener con firmeza la resolución de nunca dar mi juicio sobre las cosas cuya verdad no me es conocida con claridad $\rangle^{72}$, como forma de evitar el error, la elección por la que finalmente se inclina decisivamente es por la acción. Es más importante ser resoluto en el juicio y llevar a cabo los actos, aunque posteriormente ello implique el error:

«[...] ser en mis acciones lo más firme y resuelto que pudiera y seguir tan constante en las más dudosas opiniones, una vez determinado a ellas, como si fuesen segurísimas, imitando en esto a los caminantes que, extraviados en algún bosque, no deben andar errantes dando vueltas por una y otra parte, ni menos detenerse en un lugar, sino caminar siempre lo más derecho que puedan hacia un sitio fijo, sin cambiar de dirección por leves razones, aun cuando en un principio haya sido sólo el

68. Descartes: Pasiones del alma, art.59, p.489 (AT XI, p.376)

69. Descartes: Pasiones del alma, art.170, p.533 (AT XI, p.459)

70. Descartes: Principios de la filosofía, p.21 (nota)

71. Descartes: «Carta a la princesa Isabel de mayo de 1646», p.629 (AT IV, p.415)

72. Descartes: Meditaciones metafísicas, p.199 (AT VII, p.61)

Thémata. Revista de Filosofía $\mathrm{N}^{\circ} 56$ (2017) pp.: 103-126. 
azar el que les haya determinado a elegir ese rumbo, pues de este modo, si no llegan precisamente a donde quieren ir, por lo menos acabarán por llegar a alguna parte, en donde es de pensar que estarán mejor que no en medio del bosque» ${ }^{73}$.

Así, se rompe la interpretación de los juicios cartesianos vinculada a la búsqueda de la verdad como tarea primordial, pues Descartes reconoce que ha "exceptuado siempre las cosas que se refieren a la fe y a las acciones de la vida, cuando dije que no debemos otorgar crédito sino a las cosas que conocemos con evidencia» ${ }^{74}$. Dada la preeminencia de la acción sobre la contemplación, en los juicios prima la dimensión práctica sobre la verdad, es decir, es más importante que se realice la acción a la que el mundo nos obliga a que el conocimiento que la fundamente sea verdadero. Dado que «la vida no tolera dilaciones» ${ }^{75}$, los intereses cartesianos por la práctica se materializan en una constante defensa (AT IV, p.265; IV p.295; IV, p.411; IV, p.415; VI, p.24) por parte de Descartes de la resolución en los juicios, pues:

[...] aunque no podamos contar con demostraciones fidedignas de todo, tenemos, sin embargo, que tomar partido y hacer nuestras las opiniones que nos parezcan más verosímiles en cuanto se refieren a los usos, de forma tal que, llegado el momento de actuar, no pequemos nunca de irresolutos. Pues sólo la falta de resolución es causa de lamentaciones y arrepentimientos ${ }^{76}$.

Es más, Descartes no sólo se inclina por la práctica ordinaria frente a la contemplación de la verdad, sino que incluso reiteradamente sostiene que "Tampoco es necesario que nuestra razón no yerre nunca»" (AT II, p.35; IV, p.266; IV, p.307). Descartes, consciente de la naturaleza falible del sujeto y de la necesidad que impelen al sujeto a actuar ante los asuntos de la vida ordinaria, afirma que el error en los juicios sucede habitualmente y que ello no debe conllevar decepción alguna para el sujeto, pues «si nos atenemos siempre a lo que nos dicta la razón, no tendremos nunca motivo para arrepentirnos, aunque los acontecimientos nos hagan caer en la cuenta, pasado un tiempo, de que nos hemos equivocado» ${ }^{78}$. No importa que nuestros juicios sean verdaderos, sino que juzguemos «lo mejor que se

73. Descartes: Discurso del método, p.118 (AT VI, pp.24-5)

74. Descartes: Meditaciones metafísicas, p.334 (AT VII, pp.24-5)

75. Descartes: Principios de la filosofía, p.15 (AT IX-B, p.13)

76. Descartes: «Carta a Isabel del 15 de septiembre de 1645», p.603 (AT IV, p.295)

77. Descartes: «Carta a la Princesa Isabel del 4 de agosto de 1645», p. 587 (AT IV, pp.266-7)

78. Descartes: «Carta a la princesa Isabel del 4 de agosto de 1645», pp.586-7 (AT IV, p.266)

Thémata. Revista de Filosofía $\mathrm{N}^{\circ} 56$ (2017) pp.: 103-126. 
pueda, para obrar también lo mejor que se pueda» ${ }^{79}$ - lo que significa introducir en los juicios la certeza moral. En los juicios que atañen a la vida debemos conformarnos con la certeza moral, pues es más importante la realización del acto que su verdad. Consecuentemente, se evidencia que el proyecto epistemológico cartesiano no es el del investigador puro cuyo fin es evitar el error a toda costa, sino que el sujeto cartesiano procura juzgar de la mejor forma posible, actuando acorde a lo que su razón le determina como mejor - aunque ello pueda concluir en error.

Ahora bien, no se trata tampoco de disolver la esfera de la verdad en el proyecto cartesiano, sino de mostrar que los intereses últimos de ésta poseen un carácter eminentemente práctico. El sujeto no está necesariamente obligado a efectuar juicios vitales en todo momento ${ }^{80}, \mathrm{y}$ precisamente en esas ocasiones «en que nos dedicamos exclusivamente al problema del conocimiento» ${ }^{81}$, adquiere sentido el ejercicio de la epoché - la suspensión de los juicios que carecen de una percepción clara y distinta (AT VI, p.18; VII, pp.59-60; IX-B, p.43) - a fin de evitar el error y hallar los fundamentos metafísicos con que perfeccionar la certeza moral. No obstante, la suspensión del juicio no puede abarcar en ningún momento la esfera vital del sujeto, ya que «esta duda tan universal puede producir una gran irresolución y un gran desarreglo en las costumbres» ${ }^{82}$ de forma que «las ocasiones oportunas para actuar casi siempre pasarían antes de que pudiéramos vernos libres de todas nuestras dudas» ${ }^{83}$, dificultando la

79. Descartes: Discurso del método, p.120 (AT VI, p.28)

80. La urgencia de las circunstancias de la vida para tomar una decisión no es la misma en todas las ocasiones, y es precisamente en los momentos en que no es preciso realizar una acción práctica donde es posible la reflexión metafísica. El propio Descartes refiere, de hecho, al contexto tranquilo y libre de agitaciones que requiere la contemplación de la verdad: «[...] y no teniendo tampoco, por fortuna, cuidados ni pasiones que perturbaran mi ánimo, permanecía el día entero solo y encerrado junto a una estufa, con toda la tranquilidad necesaria para entregarme a mis pensamientos» (Discurso del método, p.109 [AT VI, p.11]); "[...] cuando mi espíritu se halle libre de toda preocupación, y habiéndome procurado un seguro reposo en una soledad apacible, me aplicaré seriamente y con libertad a destruir de manera general todas mis antiguas opiniones» (Meditaciones metafísicas, p.165 [AT VII, pp.17-8]). La búsqueda cartesiana del conocimiento precisa de unas circunstancias que permitan la abstracción más allá de los problemas mundanos. Sin embargo, esta capacidad no debe traducirse en un despreocupación respecto a la práctica de la vida, pues ésta prima ante la búsqueda de la verdad, además de que el sujeto posee una capacidad limitada de abstracción que no le permite distanciarse demasiado tiempo de los asuntos del mundo: «Sin embargo, esta resolución es ardua y laboriosa, y cierta pereza me arrastra insensiblemente al trajín de mi vida ordinaria» (Ibid., p.169 [AT VII, p.22]).

81. De Araujo, M.: op. cit., p.151

82. Descartes: «Carta a Reneri para Pollot, de marzo de 1638», pp.362-3 [trad. Olaso] (AT II, p.35)

83. Descartes: Principios de la filosofía, p.22 (AT IX-B, p.26)

Thémata. Revista de Filosofía $\mathrm{N}^{\circ} 56$ (2017) pp.: 103-126. 
toma de decisiones que garantizan la buena vida. Así, aun cuando exista una preeminencia de la acción, la búsqueda de la verdad en los juicios se preserva mientras las circunstancias lo permitan. La buena vida requiere juicios resolutos donde el sujeto se debe conformar con una certeza moral susceptible de ser perfeccionada pero que, a la postre, nunca suprimirá la posibilidad de errar. Y, precisamente el sujeto que nunca ha dejado «de hacer todo aquello que ha juzgado lo mejor [...], recibe una satisfacción tan poderosa para hacerle feliz que no los mayores esfuerzos de las pasiones tienen jamás poder suficiente para turbar la tranquilidad de su alma» ${ }^{84}$, permitiéndole gozar de una buena vida.

En definitiva, los juicios poseen una doble función vinculada a la práctica de la vida como al conocimiento de la verdad, donde la precipitación y la irresolución representan las dos formas deficientes de efectuar juicios. El carácter resoluto que Descartes propugna respecto a éstos, junto con la mayor importancia de la toma de decisiones que de la obtención de la verdad — sin importar si el sujeto finalmente yerra, pues «partiendo de la imposibilidad de juzgar siempre bien, nos queda [...] la constricción de juzgar lo mejor posible» ${ }^{85}$ - da cuenta de la preeminencia de la acción sobre la contemplación de la verdad.

\section{Conclusión}

El proyecto cartesiano no puede ser subsumido bajo la figura del investigador puro, pues, como se ha puesto de manifiesto, la meta hacia la que se dirige la propuesta de Descartes es a perfeccionar la forma en que el sujeto se conduce en relación a los «asuntos ordinarios de la vida, donde el objetivo central, hablando en general, es vivir bien y de forma feliz» ${ }^{86}$. Si bien la búsqueda de la verdad guarda un importante papel en su filosofía, se ha evidenciado cómo la esfera de la práctica vital del hombre, que lo posiciona ante los avatares de la vida ordinaria, se sitúa por encima del proceder que Descartes propone para la obtención de la verdad. En efecto, nuestras acciones vitales, resultado de juicios que nos permiten la obtención de una buena vida, no pueden estar sujetas ni a la duda radical, ni a una suspensión del juicio hasta la obtención de una percepción clara y distinta. La práctica de la vida es ubicada por Descartes al margen de los

84. Descartes: Pasiones del alma, art.148, pp.523-4 (AT XI, p.442)

85. Rodis-Lewis, G.: La Morale de Descartes, Paris: Presses Universitaires de France, 1970, p. 121

86. Marshall, J.: Descartes's Moral Theory, London: Cornell University Press, 1998, p.13

Thémata. Revista de Filosofía №56 (2017) pp.: 103-126. 
ejercicios metafísicos, en tanto que la prudencia no nos permite ocasionar una gran irresolución al sujeto ante la necesidad de tomar decisiones vitales, mostrando que la dimensión ordinaria del sujeto prima ante las disquisiciones metafísicas. Esta preeminencia de la acción sobre la contemplación de la verdad implica, por otra parte, una redefinición del papel de la certeza metafísica, cuya tarea pasa a ser la de perfeccionar la certeza moral, asumiendo el carácter inherentemente falible del ser humano —donde la supresión del error deja de constituir una tarea central. Por tanto, la búsqueda de la verdad en forma de certeza metafísica se plantea a fin de hallar "los medios de fortificar el propio entendimiento de forma tal que le resulte posible distinguir lo mejor en cuanto se hace en la vida» ${ }^{87}$. Así, dado que el sujeto precisa de actuar obligado por las circunstancias del mundo, se requieren juicios resolutos fundamentados en una certeza moral - aunque el error pueda producirse posteriormente-, porque:

[...] en lo que respecta a la práctica de la vida, no pienso de ninguna manera que haya que seguir sólo las cosas que conocemos muy claramente; al contrario, sostengo que ni siquiera hay que esperar siempre las más verosímiles, sino que a veces, entre muchas cosas por completo desconocidas e inciertas, hay que escoger una y determinarse por ella, y luego de ello no creerla con menos firmeza que si la hubiéramos escogido por razones ciertas y muy evidentes ${ }^{88}$.

Cabe añadir, a fin de subvertir completamente la interpretación del investigador puro, que Descartes reconoce en diversas ocasiones que las disquisiciones metafísicas no deben ocupar al sujeto demasiado tiempo, en tanto que:

[...] sería muy perjudicial tener el entendimiento ocupado en esa meditación con excesiva frecuencia, puesto que, en tal caso, no podría dedicarse de forma adecuada a las funciones de la imaginación y los sentidos. Opino, pues, que lo más aconsejable es contentarse con conservar en la memoria y en las creencias las conclusiones anteriormente aceptadas y dedicar luego el tiempo restante al estudio y a los pensamientos en los que, junto con el entendimiento, intervienen la imaginación y los sentidos ${ }^{89}$.

Descartes sostiene que una excesiva ocupación respecto a los asuntos metafísicos puede resultar muy perjudicial para el sujeto, pues de ese modo "se separa demasiado la mente de las cosas físicas y sensibles, ha-

87. Descartes: «Carta del 15 de septiembre de 1645 a la princesa Isabel», p.600 (AT IV, p.291).

88. Descartes: Meditaciones metafísicas, p.263 (AT VII, p.149)

89. Descartes: «Carta del 28 de junio de 1643 a la princesa Isabel», pp.559-60 (AT III, p.695)

Thémata. Revista de Filosofía $\mathrm{N}^{\circ} 56$ (2017) pp.: 103-126. 
ciéndola inepta para examinarlas, cosa que sería, sin embargo, muy deseable que los hombres hicieran, porque ello resultaría de gran utilidad para su vida ${ }^{90}$. De ahí que Descartes afirme repetidamente que debemos, en el plano metafísico, deshacernos de todas nuestras opiniones una vez en la vida (AT II, p.35; III, p.695; V, p.165; VII, p.17; IX-B, p.25). Recordemos que los sentidos representan uno de los pilares que guían nuestra vida ordinaria (AT VI, p.81; VII, p.351), y el dedicar demasiado tiempo a los asuntos metafísicos puede trastocar seriamente elementos sobre los que conducimos nuestras acciones, por ello se deben dedicar «muy pocas horas a los pensamientos que mantienen ocupada a la imaginación, y poquísimas horas al año a los que sólo mantienen ocupado el entendimiento, empleando todo el tiempo sobrante en dar suelta a los sentidos y descanso de la mente» ${ }^{91}$. De este modo, concluye Descartes que «no es preciso dedicarse tanto a las Meditaciones ni a las cosas metafísicas»" ${ }^{92}$, pues "no hay necesidad de tomar tanto tiempo para leer mis Meditaciones a fin de entender mis principios» ${ }^{93}$, sino que «basta con conocer el primer libro de los Principios, en el que se contiene lo que se necesita saber de metafísica para la física ${ }^{94}$. Así pues, la búsqueda de la verdad no constituye la tarea primordial del proyecto cartesiano, sino que la adquisición de las certezas metafísicas solo representa un importante paso hacia la mejora de la conducción del sujeto en el mundo.

En suma, la preeminencia de la práctica de la vida garantiza la formulación de juicios resolutos sustentados por una certeza moral que permiten la acción ante las circunstancias vitales, mejorando nuestra conducción y, consecuentemente, contribuyendo a gozar de una buena vida. No se trata de suprimir la importancia de la búsqueda de la verdad en el proyecto cartesiano, sino que, observando que Descartes encarna una cosmovisión activa del sujeto en el mundo dirigida a la intervención en la naturaleza, el papel de la metafísica cartesiana se redefine en relación a sus intereses prácticos.

\section{Referencias bibliográficas}

Agustín de Hipona: Confesiones, Madrid: Gredos, 2010.

Broughton, J.: Descartes's Method of Doubt, Princeton: Princeton

90. Descartes: Conversación con Burman, p.440 (AT V, p.165)

91. Descartes: «Carta a Isabel del 28 de junio de 1643», p.558 (AT III, pp.692-3)

92. Descartes: Conversación con Burman, p.440 (AT V, p.165)

93. Descartes: «Carta a Chanut del 26 de febrero de 1649» (AT V, p.291).

94. Descartes: Conversación con Burman, p.440 (AT V, p.165)

Thémata. Revista de Filosofía $\mathrm{N}^{\circ} 56$ (2017) pp.: 103-126. 
University Press, 2002.

Brown, D.: Descartes and the Passionate Mind, Cambridge: Cambridge University Press, 2006.

Cottingham, J.: How to read Descartes, Croydon: Granta, 2008

De Araujo, M.: Scepticism, Freedom and Autonomy, New York: Walter de Gruyter, 2003.

Descartes, R.: Oeuvres de Descartes (XII Vol.), Adam, C. \& Tannery, P. (eds.), París: Leopold Cerf, 1897-1913.

- Meditaciones metafísicas, Peña, V. (trad.): Madrid: Alfaguara, 1977.

- Discurso del método, Dióptrica, Meteoros y Geometría, Quintás, G. (trad.): Madrid, Alfaguara, 1981.

- Principios de la filosofía, Quintás, G. (trad.): Madrid, Alianza Editorial, 1995.

- Descartes, Flórez, C. (Ed.): Madrid: Gredos, 2011.

Dibon, P.: "Scepticisme et orthodoxie reformée dans la Hollande du Siècle d'Or» en Popkin, R., \& Schmitt, C. (eds.): Scepticism from the Renaissance to the Enlightenment, 1987.

Diógenes Laercio: Vidas de los Filósofos Mlustres, Madrid: Alianza, 2011.

Guenancia, P.: Lire Descartes, Paris: Gallimard, 2000.

Hamelin, O.: Le Système de Descartes, Paris: Félix Alcan, 1921.

Jolley, N.: "The relation between theology and philosophy», en Garber, D. \& Ayers, M. (eds.): The Cambridge History of Seventeenth Century Philosophy (Vol. I), Cambridge: Cambridge University Press, 1998.

Kenny, A.: Descartes. A study of his philosophy, New York: Random House, 1968.

Kristeller, P.O.: "Philosophy and Humanism in Renaissance Perspective» en O'Kelly (ed.): The Renaissance Image of Man and the World, Ohio: Ohio State University Press, 1966.

Marion, J.L.: Sur l'Ontologie Grise de Descartes, Paris: Vrin, 2000

Markie, P.: Descartes's Gambit, Ithaca: Cornell University Press, 1986.

Marshall, J.: Descartes's Moral Theory, London: Cornell University Press, 1998.

Menn, S.: «The Intellectual Setting», en Garber, D. \& Ayers, M. (eds.): The Cambridge History of Seventeenth Century Philosophy (Vol. I), Cambridge: Cambridge University Press, 1998.

Naaman-Zauderer, N.: Descartes' Deontological Turn. Reason, Cambridge: Cambridge University Press, 2010.

Popkin, R.: La Historia del Escepticismo desde Erasmo hasta Spinoza, México: Fondo de Cultura Económica, 1983.

Ragland, C.P.: The Will to Reason. Theodicy and Freedom in Descartes, Oxford: Oxford University Press, 2016.

Rodis-Lewis, G.: La Morale de Descartes, Paris: Presses 
Universitaires de France, 1970.

Schmitt, C.: «Philosophy and science in sixteenth-century universities: some preliminary comments» en Murdoch, J. (ed.): The Cultural Context of Medieval Learning, Boston: Reidel Publishing Company, 1975.

Williams, B.: Descartes. El proyecto de la investigación pura, Madrid: Cátedra, 1996.

Wilson, M.: Descartes, London: Routledge \& Kagan Paul, 1978. 